statistically significant association was only detected between school backpack weight and the emergence of changes in the spinal curvature at the thoracic region $(p=0.036)$, in the right tilt position.

\title{
Conclusions:
}

There seems to be an association between the school backpack weight and the appearance of postural changes in the sagittal plane of almost all the regions of the spine analysed.

\section{Association between School Backpack Weight and the Appearance of Postural Changes in School-Age Children}

C Francisco $^{1}$, J Silva ${ }^{1}$, S Sousa ${ }^{1}$, D Gonçalves ${ }^{1}, N^{\prime}$ Azevedo ${ }^{1}$,

L Rodrigues" ${ }^{1}, \mathrm{G}$ Pacheco'

${ }^{1}$ CICS - Centro Interdisciplinar em Ciências da Saúde, ISAVE - Instituto

Superior de Saúde, Portugal

Introduction:

According to multiple authors, the use of backpacks with excessive weight might be associated with the prevalence of postural changes of the spine (e.g., Bartlett \& Birmingham, 003; Falsarella, Bocaletto, Deloroso, \& Cordeiro, 2008), creating instability and a higher susceptibility to spinal injuries (Ries, Martinello, Medeiro, Cardoso \& Santos, 2012)

Objectives:

To verify the existence of association between the weight of school backpacks and the emergence of postural changes in a sample of students aged between 10 and 18 years old, from Amares, Braga.

\section{Methods:}

480 students ( 245 females and 235 males) from public middle schools in Amares county, aged between 10 and 18 years old, were given an individual questionnaire regarding their sociodemographic information, activities of their daily living and clinical history. The weight of each student and its school backpack was recorded, together with a dynamic evaluation of the spine in the frontal and sagittal anatomical planes using the non-invasive measuring instrument $\operatorname{Idiag}^{\circledR}$ Spinal Mouse ${ }^{\circledR}$. The student population was then divided in two groups: students with "normal" backpack weight $(<20 \%$ bodyweight) and students with "excessive backpack weight (> 20\% bodyweight). Chi-Square (X2) tests were executed in IBM SPSS to verify the level of association between variables.

\section{Results:}

In the sagittal plane, a statistically significant association was detected between school backpack weight and the appearance of postural changes in the thoracic, lumbar and sacral regions of school-age children $(\mathrm{p}<0,05)$. In the frontal plane, a 